\title{
Structural and Morphological Properties of $\mathrm{TiO}_{2}$ Nanotubes Fabricated via Electro-anodization Process
}

\author{
Johannes Zanoxolo Mbese* and Ziyanda Madikizela \\ Department of Pure and Applied Chemistry, University of Fort Hare, South Africa
}

\begin{abstract}
Electro-anodization of thin Ti film deposited on glass substrate by RF sputtering technique was employed to fabricate $\mathrm{TiO}_{2}$ Nanotubes (TNTs) annealed from $350^{\circ} \mathrm{C}$ to $650^{\circ} \mathrm{C}$. The morphological analysis were done using Scanning Electron Microscopy (SEM), which showed the change in the surface morphology with increase in annealing temperature. The structural analysis was performed using X-ray Diffraction (XRD) and Raman spectroscopy. XRD revealed the presence of anatase phase $\mathrm{TiO}_{2}$ with most intense anatase peak found at $550^{\circ} \mathrm{C}$, at $2 \theta$ of $28,9^{\circ}(101)$. Raman revealed the presence of only anatase phase of $\mathrm{TiO}_{2}$, and showed well-improved crystallinity of the TNTs upon increasing in annealing temperature.
\end{abstract}

Keywords: Electro-anodization; Fabrication; Annealing; Crystallinity

\section{Introduction}

Several techniques used in the preparation of TNTs include sol-gel method [1], hydrothermal method [2], template assisted technique [3] and electrochemical anodization [4]. Electrochemical anodization has been a method of choice to grow ordered nanotubes of controllable pore size and good uniformity and is a cheap and simple technique [4]. The drawbacks of TNTs include the limitation of TNTs by the nature of the substrate, most of the TNTs are grown on metal substrate (e.g. Ti foil). The presence of the metal substrate inhibits application of TNTs in functional micro-devices such as DSSCs and other electrochromic devices that require a transparent metal oxide electrode $[5,6]$. Some researchers have counteracted the said drawbacks by successfully developed the technology to grow the nanotube arrays from thin titanium films using anodization on a variety of substrates e.g. glass $[7,8]$. It is of high interest to form nanotube layers from thin Ti films deposited on substrates, such as silicon wafer or glass. In nature, titanium dioxide is found mainly in three polymorphs, anatase, rutile and brookite [9]. The techniques used for depositing titanium films includes evaporation technique, however in this study we used Radio Frequency (RF) sputtering technique.

\section{Experimental Section}

Anodization is an electrolytic technique used to develop a passive layer at the anode. Figure 1 shows the schematic diagram of

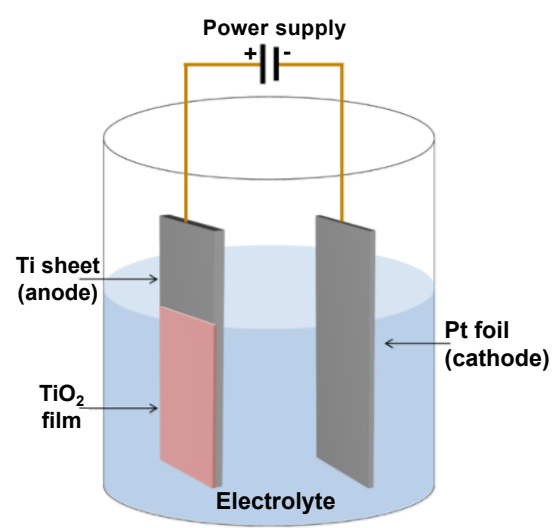

Figure 1: Schematic diagram of anodizing cell. anodizing cell. The electrolyte solution prepared was transferred into electrochemical Teflon cell with titanium film $(10 \mu \mathrm{m})$ from (Alfa Aesar A Johnson Matthey company) sputter coated glass substrate of dimensions $(2 \times 2 \mathrm{~cm})$. The substrate was connected to the positive wire of the (PS $8000 \mathrm{~T}$ ) variable DC power supply using banana plugs (nickel plated brass) purchased from (RS Components) to form an anode electrode and platinum foil $(1 \mathrm{x} 1 \mathrm{~cm})$ and $(0.025 \mathrm{~mm}$ in thickness, 99.9\% purity) from (Alfa Aesar A Johnson Matthey company) was connected to the negative wire to form the cathode electrode. The gap between the electrodes was kept constant at $2 \mathrm{~cm}$. Magnetic stirrer was used so as to make sure that the local current is uniform throughout the solution and also to control the viscosity of the solution. The two electrodes attached to the wires using an alligator crocodile clips lead medium. The TRMS Digital Multimeter (C.A 5273) was used to monitor the temperature of the electro-anodization cell and electrolyte throughout the electrochemical anodization process. Electrochemical anodization of glass coated titanium was carried out at $60-100 \mathrm{~V}$ for 24-72 hours at ambient temperatures. After 24 hours the DC power supply cooled off by shutting it down for about 3 hours, by so doing preventing overheating or any kind of system breakdown.

The anodization was carried out at different voltages ranging from 60-100 V and in each case the voltage was held constant for 12 hours. After the anodization process was done, the as prepared TNTs was again cleaned in ethanol, acetone and subsequently rinse in DI water. The anodised TNTs were allowed to dry in air. Furthermore, the TNTs were then annealed at different temperatures starting from $350^{\circ} \mathrm{C}$, $450^{\circ} \mathrm{C}, 550^{\circ} \mathrm{C}$, and $650^{\circ} \mathrm{C}$. Finally, the prepared and annealed TNTs were characterized using SEM, XRD and CRS.

*Corresponding author: Johannes Zanoxolo Mbese, Lecturer and HOD, Department of Pure and Applied Chemistry, University of Fort Hare, Alice, South Africa, Tel: +27 40602 2055; E-mail: jmbese@ufh.ac.za

Received February 14, 2019; Accepted February 25, 2019; Published March 05, 2019

Citation: Mbese JZ, Madikizela Z (2019) Structural and Morphological Properties of $\mathrm{TiO}_{2}$ Nanotubes Fabricated via Electro-anodization Process. J Material Sci Eng 8: 509. doi: 10.4172/2169-0022.1000509

Copyright: @ 2019 Mbese JZ, et al. This is an open-access article distributed under the terms of the Creative Commons Attribution License, which permits unrestricted use, distribution, and reproduction in any medium, provided the original author and source are credited. 


\section{Results and Discussions}

XRD were performed to obtain the conclusive crystallographic structure and phase properties of TNTs. Figure 2 shows the XRD patterns of the as anodized and annealed titanium dioxide nanotubes grown on functional substrates. At $350^{\circ} \mathrm{C}$, the XRD diffractogram in the wide angle range of $2 \theta\left(20^{\circ}<2 \theta>80^{\circ}\right)$ have revealed peaks at $29.43^{\circ}$, $45.10^{\circ}, 56.52^{\circ}, 64.92^{\circ}$ and $74.81^{\circ}$ equivalent to the planes (101), (112), (200), (211) and (204) belonging to a well crystallized anatase phase of $\mathrm{TiO}_{2}$ (anatase XRD JCPDS Card no. 78-2486) [10]. The emergence of rutile is attributed to the "substrate effect", thus, when the metallic substrate was oxidized, a thin compact rutile layer formed at metal/ oxide interface, which initiates anatase to rutile phase transformation [10]. This shows that as the annealing temperature increases, there is an improvement in the crystallinity of the TNTs-FS as the crystalline size decreases. This is in accord with the SEM results showing improved surface morphology of the TNTs-FS as the annealing temperature increases.

Surface and inner morphological characterization of the TNT samples were evaluated using a Scanning Electron Microscopy (SEM). Figure 3 shows Scanning Electron Microscopy (SEM) of TNTs on FTO glass substrate annealed at $650^{\circ} \mathrm{C}$. While the structural characterization of titanium dioxide nanotubes was investigated using confocal Raman spectroscopy coupled with Raman imaging. Nature of lattice present, structural make-up of phase, degree of crystallinity, and micro-strain and orientation of crystallites was determined from XRD with incident angles ranging from $20^{\circ} \mathrm{C}$ to $80^{\circ} \mathrm{C}$ [11]. SEM was used to characterize the diameter and the length of the tubes along with the structural morphology. SEM provides high resolution images and surface morphology of the sample by focusing electron beam across the surface and detecting backscattered electron signal.

The surface morphology of TNTs (Figure 3(a)) reveals that increasing annealing temperature brings about a slight change in surface morphology of TNTs. The cross sectional view SEM images also revealed smoother TNTs walls as shown in Figure 3(b). The histogram on Figure 3(c) shows that the pore diameter ranges from 125-160 nm, which is smaller than the one observed in $350^{\circ} \mathrm{C}$ and $450^{\circ} \mathrm{C}$ annealing temperatures. Figure 3(d) also unveiled a blue area corresponding to the blue spectrum with Raman modes and vibrational frequencies at $156.51 \mathrm{~cm}^{-1}\left(\mathrm{E}_{\mathrm{g}}\right), 206.36 \mathrm{~cm}^{-1}\left(\mathrm{E}_{\mathrm{g}}\right), 402.57 \mathrm{~cm}^{-1}\left(\mathrm{~B}_{\mathrm{gg}}\right), 520.55 \mathrm{~cm}^{-1}\left(\mathrm{~A}_{\mathrm{lg}}\right)$ and $638.79 \mathrm{~cm}^{-1}$ all belonging to a well crystallized anatase phase of $\mathrm{TiO}_{2}$.

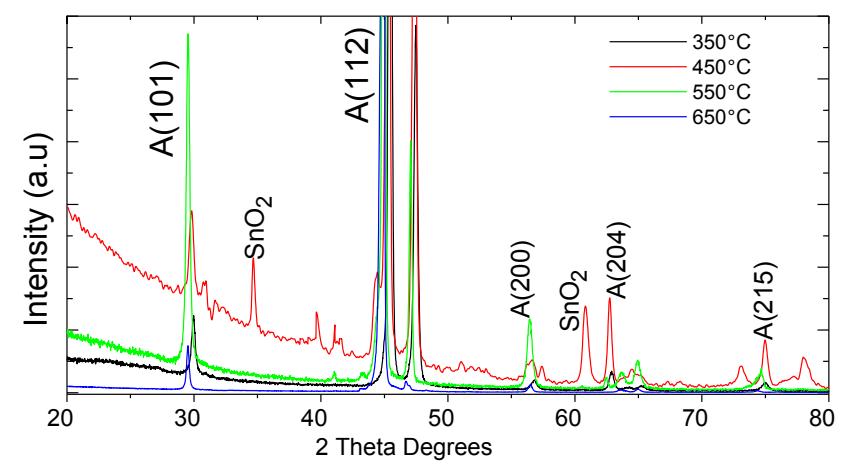

Figure 2: XRD spectra of the anodized TNTs grown on FTO glass substrate prepared at $60 \mathrm{~V}$ in $\mathrm{NH}_{4} \mathrm{~F} /$ glycerol based solution and annealed at $350^{\circ} \mathrm{C}$ $450^{\circ} \mathrm{C}, 550^{\circ} \mathrm{C}$ and $650^{\circ} \mathrm{C}$.
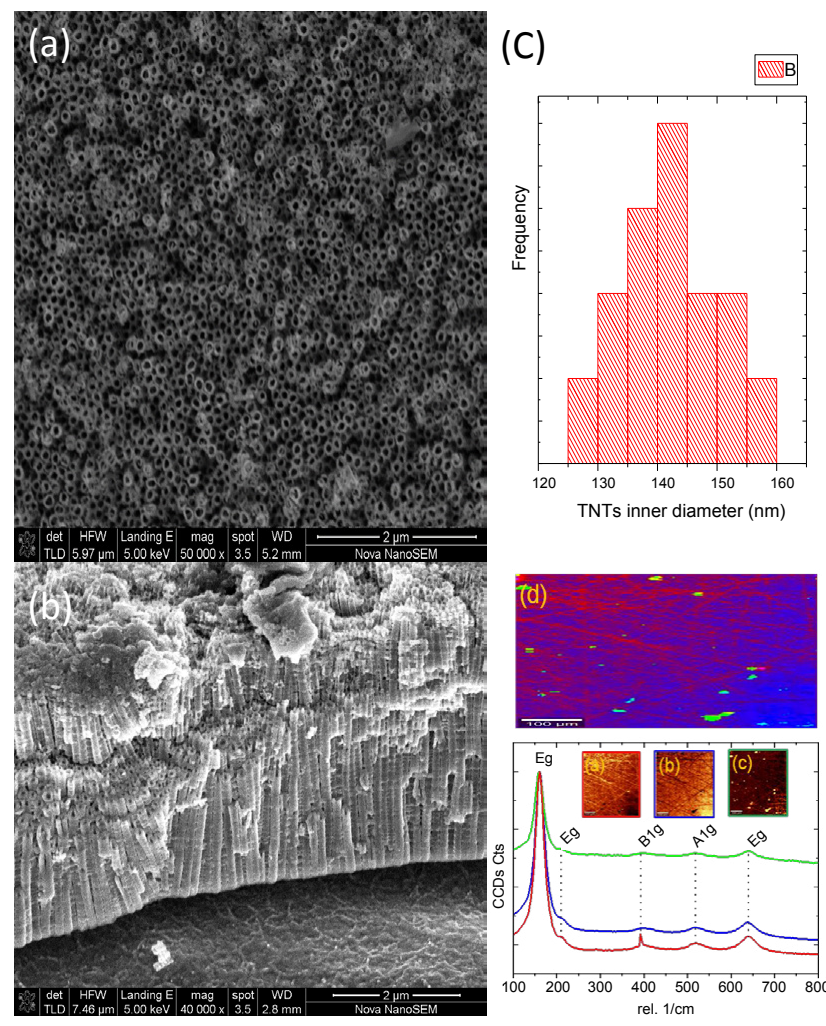

Figure 3: SEM micrographs of TNTs on FTO glass substrate annealed at $650^{\circ} \mathrm{C}$ (a) Surface SEM images of TNTs, (b) Cross sectional SEM images, (c) Histogram showing pore size distribution and (d) Large area scan of TNTs annealed at $650^{\circ} \mathrm{C}$.

\section{Conclusion}

Crystalline $\mathrm{TiO}_{2}$ nanotubes were successfully grown on FTO glass substrate by RF-Sputtering of the Ti films which was then followed by electro-anodization. SEM has revealed that the increase in annealing temperature within a range of $350^{\circ} \mathrm{C}-650^{\circ} \mathrm{C}$ led to well improved morphology of $\mathrm{TiO}_{2}$ nanotubes and the pore diameter started to increase. TNTs material grown on FTO glass substrate displayed exceptional stability with no rapturing of the TNTs, unlike other TNTs prepared by other synthetic techniques. The increase in pore diameter of the nanotubes means increased surface area of the nanotubes, which means more loading of the dye, thus more number of photons generated, hence well-improved solar cell performance. XRD analysis of $\mathrm{TiO}_{2}$ nanotubes confirmed anatase phase. Raman microscopy measurements showed a mutual agreement with SEM and XRD.

\section{Acknowledgment}

The authors acknowledged with thanks to Dr R Taziwa, for assisting ZM through the entire experiments and sample characterizations. We acknowledge the financial support from Govan Mbeki Research and Development Centre (GMRDC), University of Fort Hare and NRF-Sasol Inzalo foundation for postgraduate scholarship.

\section{References}

1. Xiao L, Zhang H, Scanlon E, Ramanathan LS, Choe EW, et al. (2005) Hightemperature polybenzimidazole fuel cell membranes via a sol-gel process. Chem Mater 17: 5328-5333.

2. Byrappa K, Yoshimura M (2012) Handbook of hydrothermal technology William Andrew.

3. Myahkostupov M, Zamkov M, Castellano FN (2011) Dye-sensitized photovoltaic 


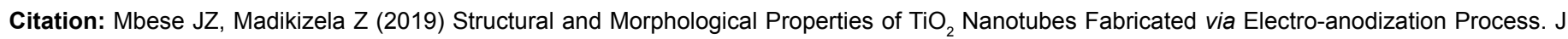
Material Sci Eng 8: 509. doi: 10.4172/2169-0022.1000509

properties of hydrothermally prepared TiO2 nanotubes. Energy Environ Sci 4 : 998-1010.

4. Ou HH, Lo SL (2007) Review of titania nanotubes synthesized via the hydrothermal treatment: fabrication, modification, and application. Sep Purif Technol 58: 179-191.

5. Mor GK, Varghese OK, Paulose M, Grimes CA (2005) Transparent highly ordered TiO2 nanotube arrays via anodization of titanium thin films. Adv Funct Mater 15: 1291-1296.

6. Yu X, Li Y, Wlodarski W, Kandasamy S, Kalantar-Zadeh K (2008) Fabrication of nanostructured $\mathrm{TiO}_{2}$ by anodization: A comparison between electrolytes and substrates. Sens Actuators B 130: 25-31.

7. Chu SZ, Inoue S, Wada K, Hishita S, Kurashima K (2005) Self-organized nanoporous anodic titania films and ordered titania nanodots/nanorods on glass. Adv Funct Mater 15: 1343-1349.

8. Macak JM, Tsuchiya H, Berger S, Bauer S, Fujimoto S, et al. (2006) On wafer $\mathrm{TiO} 2$ nanotube-layer formation by anodization of Ti-films on Si. Chem Phys Lett 428: 421-425.

9. Bokhimi X, Morales A, Aguilar M, Toledo-Antonio JA, Pedraza F (2001) Local order in titania polymorphs. Int J Hydrogen Energy 26: 1279-1287.

10. Schulte KL, DeSario PA, Gray KA (2010) Effect of crystal phase composition on the reductive and oxidative abilities of $\mathrm{TiO}_{2}$ nanotubes under $\mathrm{UV}$ and visible light. Appl Catal B 97: 354-360.

11. Rietveld HM (1967) Line profiles of neutron powder-diffraction peaks for structure refinement. Acta Crystallogr 22: 151-152. 